\title{
Technology Adoption in Education-Based Business Services
}

\author{
Lusianus Kusdibyo $^{\mathrm{a} *}$, Hewage Lakshi Krishani Perera ${ }^{\mathrm{b}}$, Gundur Leo ${ }^{\mathrm{c}}$ \\ ${ }^{a}$ Associate Professor, Department of Business Administration, Politeknik Negeri Bandung, Indonesia \\ ${ }^{b}$ Lecturer in Marketing, School of Business, Melbourne Institute of Technology, Australia \\ ${ }^{\mathrm{c}}$ Senior Lecturer, Department of Business Administration, Politeknik Negeri Bandung, Indonesia
}

Received 01 March 2019; accepted 13 May 2019

\begin{abstract}
The objectives of this study are two folds. First, is to identify the advantages and disadvantages factors of electronic learning's adoption. Secondly is to measure the influence of innovation adoption components toward users' attitude in using electronic learning. A mixed method of study was carried out in response to the research's objectives. The qualitative approach was conducted by means of interviewing 25 participants of users to identify elearning advantages and disadvantages. The quantitative approach was used to test the hypotheses. A questionnaire was distributed to 313 elearning system users. The results show that the three advantages and disadvantages of e-learning adoption factors were formed. SEM-Smart PLS was used to test the hypothetical relationships. The results indicate that three dimensions of innovation diffusion significantly influenced the attitude toward e-learning, while two dimensions were not significant. The findings suggest that education-based business services should use the advantages factors and influential dimensions to promote their teachinglearning services delivery and eliminate weaknesses and insignificant dimensions.
\end{abstract}

\section{KEYWORDS}

Innovation diffusion

Education business

E-learning

Attitude

Advantage-

disadvantage

\section{INTRODUCTION}

Higher education in Indonesia as a form of education-based business services is facing the problem of inefficiencies. This problem stems from the lack of use of technology in teachinglearning service delivery. Most of higher education-based business services in the country have not utilized the use of information technology, such as electronic learning or e-learning and other online education services. If universities do not change their method in delivering their learning services, it will result in deterioration of quality and will not be able to compete with foreign universities so that the universities will lose businesses as consumers choose to study in neighboring countries such as Singapore and Malaysia, which offer better quality in the teachinglearning delivery process. Adopting information technology of electronic learning is an urgent need for Indonesian universities, particularly in facing the new industrial era of 4.o. Although, 
few Indonesian universities have been mandatory to use e-learning, lecturers and students' attitude toward e-learning is still a question. A better understanding of users' attitude in adopting e-learning will provide the possibility of better e-learning acceptance in the future.

E-learning encourages new ways of learning and thinking. Liaw and Huang (2013) note that e-learning will increase collaboration and interaction between students; replacing previous passive learning. The authors claim that e-learning creates an interactive atmosphere on-line through computer-based technology, such as video conferencing, online reference, personalized coaching, team projects, chat rooms, discussion groups and tutorials (Liaw \& Huang, 2013). Most of these learning approaches cannot be done traditionally. The result of using e-learning is a fast learning process (Liao \& Lu, 2008; Truong, 2016). Therefore, the adoption of innovations in elearning cannot be avoided to achieve higher education institutes' competitiveness. E-learning has more advantages over traditional learning method as it increases efficiency in teaching and learning service delivery by overcoming a limitation of classrooms. Efficiency in terms of costs, time and space is important for the sustainability of any businesses include in education-based service businesses. With great efficiency in the teaching-learning process and faster learning for students, higher education institutes will have a strong competitive position over their competitors.

E-learning is an innovational teaching tool in education businesses because it offers a new way in the process of learning compared to traditional learning. The Innovation Diffusion Theory (Rogers, 2003) can explain well how innovation is adopted by consumers, how long the innovation spreads, and whether an innovation succeeds or fails to bring changes in the process. However, research that investigates diffusion of e-learning innovations in Indonesia higher education businesses is still rare. Therefore, this paper is aimed to find out two folds: first, to identify the advantages and disadvantages factors of electronic learning's adoption and second, to measure the influence of innovation adoption components toward users' attitude in using electronic learning. The results of this research will contribute to the development of e-learning adoption in Indonesian higher education businesses.

\section{LITERATURE REVIEW}

\section{Electronic Learning as an Innovation}

Some scholars have provided a definition of e-learning. Liaw (2008) defines e-learning as using network technologies to create, foster, deliver and facilitate learning, anytime and anywhere. Shee and Wang (2008) define e-learning as any form of electronic equipment used for education purposes; utilizing electronic media in its content delivery. These definitions provide insight that the base of e-learning is learning through electronic media. Thus, e-learning can change people's approach to learning because e-learning provides another alternative to traditional face-to-face education. E-learning not only conveys traditional learning through the internet but also creates innovative new ways to achieve learning material through the desired environment (Liao \& Lu, 2008). Hence, e-learning provides new learning opportunities that did not exist before (Duan, He, Feng, Li, \& Fu, 2010).

Past studies indicate that compared to traditional learning, e-learning has many advantages (Liaw \& Huang, 2013). The advantages include flexibility, comfort, easy access, consistency and repetition of material that is not yet understood (Fernández, Peralta, Benítez, \& Herrera, 2014). Further, Bouhnik and Marcus (2006) identify four advantages of using e-learning including (1) 
learners have the freedom to learn the material being studied, (2) learners reduce the limitations of time to attend lectures, (3) learners are free to express their opinions and ask questions and (4) learners have access to related subjects and materials. Chang (2016) summarizes the advantages of e-learning in four groups, namely: saving costs, improving learning, providing benefits for students, providing benefits for lecturers and providing benefits to the organization. However, Arkorful and Abaidoo (2015) note that the absence of personal interactions between lecturers and students as the most dominant weakness of e-learning. Therefore, not all teachinglearning processes can be carried out with e-learning, especially learning that requires an encounter between lecturers and students, as in practical subjects.

Most literatures on e-learning focus on acceptance of e-learning technology, for example; Mohammadi (2015) uses TAM (Technology Acceptance Model) and IS (Information System) to investigate users' view of e-learning, Chu and Chen (2016) use TPB (Theory Planned Behavior) to identify users' intention on using e-learning, similarly Okazaki and dos Santos (2012) use TPB to study e-learning adoption in Brazil. Boateng, Mbrokoh, Boateng, Senyo, and Ansong (2016) investigate e-learning adoption using extended TAM which involves culture. Tarhini, Masa'deh, Al-Busaidi, Mohammed, and Maqableh (2017) utilize extended UTAUT (Unified Theory of Acceptance and Use of Technology) to study factors influencing e-learning adoption. Duan et al. (2010) identify the acceptance and success of e-learning technology at the level of individuals and academic institutions. They conclude that the most famous model used in technology acceptance research is TAM. Because e-learning is an innovative way of learning for many people, it is quite feasible to use the Theory of Diffusion of Innovation (TDI) in examining the adoption of e-learning (Duan et al., 2010), as is done in this research.

\section{Understanding Adoption of Innovation}

The Theory of Diffusion of Innovation (TDI), which was originally developed by Rogers (1995), according to Liaw and Huang (2013) is the most feasible theory to explain technology adoption or innovation. Rogers (2003) notes that innovation is a notion, action or item that is considered new by someone. The novelty of innovation is measured subjectively according to the views of individuals who receive it. If an idea is considered new by someone, then it is an innovation for that person. The new concept in innovative ideas does not have to be new at all. Further, Rogers (2003) also maintains that adoption is the decision to use innovation entirely as a series of the best actions available, while diffusion according to Makkonen and Johnston (2014) is a process whereby innovation is transferred continuously through particular networks among associates of the social organisms.

The diffusion innovation consists of four elements based on the above definition, namely: innovation, communication channels, time and social systems. Rogers (2003) describes innovation as an idea, design, or practice which is accepted as something new by individuals or other units that adopt it. Innovation may have been found in the past, but if someone accepts it as a novelty, it is still called innovation for them. The renewal characteristics of adoption are related to the three stages of the innovation adoption process, namely; knowledge, persuasion and decision. Uncertainty is a barrier to innovation adoption. The consequences of innovation can produce insecurity. Consequences are alterations that happen to a social system or an individual because of adoption (Rogers, 2003). To diminish uncertainty in embracing an innovation, people need to be educated about the advantages and drawbacks so that they are aware of all the consequences. 
The second component of the diffusion process of innovation is the communication channel. Rogers (2003) explains communication is a method where members form and distribute information with each other to achieve mutual understanding. This communication occurs through channels between the source and the recipient. A source is an organization or individual that makes a message. Channels are means that allow messages to flow from the source to the recipient. Rogers (2003) explains diffusion as a particular form of relationship which contains the following communication components: innovation, two persons or other units of adoption and communication channels. The mass media and interpersonal communication are examples of two channels of communication. Rogers (2003) says that diffusion is a social legal action that implicates the relationship between interpersonal communications. For that interpersonal channels are better able to fashion or change attitudes held by someone.

As a process approach, diffusion theory combines time in terms of the level and shape of the process (Makkonen \& Johnston 2014). Time refers to the period of time needed by people in a society to adopt an innovation. This is the period of time needed by people to accept new ideas, for example, hand phones need time to spread the spells of people when introduced to the market as well as e-learning takes time to be accepted by lecturers and students.

The final component is the social system, which is a series of interrelated units involved in solving problems to achieve a common goal. Because the diffusion of innovations occurs in social systems, it is surely influenced by social structures and systems. The structure is a pattern of unit settings in a system. The characteristic of the social system influences individual innovation, which is the key standard for classifying adopters.

\section{Attributes of Innovation and Adoption}

Rogers (2003) describes the process of diffusion of innovation as a reduction in the process of uncertainty and proposing attributes of innovation to help reduce uncertainty about innovation. The attributes of innovation include five characteristics, namely; Relative Advantages, Compatibility, Complexity, Trialability, and Observability. Rogers (2004) states that individual views of these five features can envisage the level of adoption of innovation. Although there have been many researches on diffusion related to the nature of the adoption category, but little attention is given to adoption rates in relation to the effect of innovation perceived characteristics. Rogers (2004) defines adoption rates as relative speeds at which an innovation is implemented by community. The number of consumers or individuals who adopt innovation in a given period is the degree of adoption of an innovation. The innovation perceived attributes are important predictors of adoption rates.

Relative advantage is an innovation level considered better or superior compared to whatever existed (Lee, Hsieh, \& Hsu, 2011). This can be measured by several factors, such as economic factors, social prestige, comfort and satisfaction. The greater the relative advantage felt by adopters, the faster the innovation can be adopted.

Compatibility is to what extent the innovation is considered consistent with prevailing values, past experience and needs adopters (Lee et al., 2011; Zhang, Wen, Li, Fu, \& Cui, 2010). If a particular innovation or new idea does not match the prevailing values and norms, that innovation cannot be easily adopted.

Complexity is to what extent innovation is considered difficult to comprehend and use (Zhang et al., 2010). There are certain innovations that are easily understood and used by adopters and some are the opposite. The more easily an innovation is understood by adopters, the faster that innovation can be adopted. 
Trialability is to what extent an innovation can be tested to a certain extent (Lee et al., 2011). An innovation that can be tested in real settings will generally be more quickly adopted. So, in order to be quickly adopted, an innovation must be able to express its superiority.

Observability is to what extent the outcomes of an innovation can be seen by others (Lee et al. 2011). The easier a person sees an innovation, the more likely the person or group to adopt it. The greater the relative advantage, suitability, ability to be tested, the ability to be observed and the smaller the complexity, the more likely an innovation to be adopted (Zhang et al. 2010).

\section{Attitudes towards the Use of E-learning}

Attitudes are individual characteristics that describe positive or negative behaviors and reflections of feelings and knowledge about certain concepts or subjects (Hussein, 2017). Attitudes have three components; namely affection, cognition and behavior which refer to the level of one's preferences, one's knowledge of the object being addressed and the reactions as well as tendencies towards the object (Mantle-Bromley, 1995). Based on a study of instructional technology, Bruess (2003) states that attitude has an important role in influencing student's learning in the classroom. This is reinforced by a research conducted by Wang and Wang (2009) which states that the desires and perceptions of the use of e-learning are influenced by student's attitudes towards computers.

Many previous studies regarding e-learning technology adoption show that attitude is an important predictor on e-learning adoption (Park, 2009; Tosuntaş, Karadağ, \& Orhan, 2015). A research by Cheung and Vogel (2013) shows that positive attitudes of users will encourage greater intentions of using e-learning technology. Wang and Wang's (2009) study found that the intention to use web-based learning is significant with actual use. However, a study by Duan et al. (2010) shows only Compatibility and Trialability that have a significant effect on the intention to adopt e-learning.

The discussion presented in the literature review provides an analysis of the interrelationships between variables, is illustrated in the research model and becomes the basis for developing hypotheses that will be further tested and written as follows;

$\mathrm{H}_{1}$ : Relative advantage positively affects the attitude towards e-learning

$\mathrm{H}_{2}$ : Compatibility positively influences the attitude towards e-learning

$\mathrm{H}_{3}$ : Complexity negatively influences the attitude towards e-learning

$\mathrm{H}_{4}$ : Trialability has a positive effect on the attitude towards e-learning

$\mathrm{H}_{5}$ : Observability has a positive effect on the attitude towards e-learning 


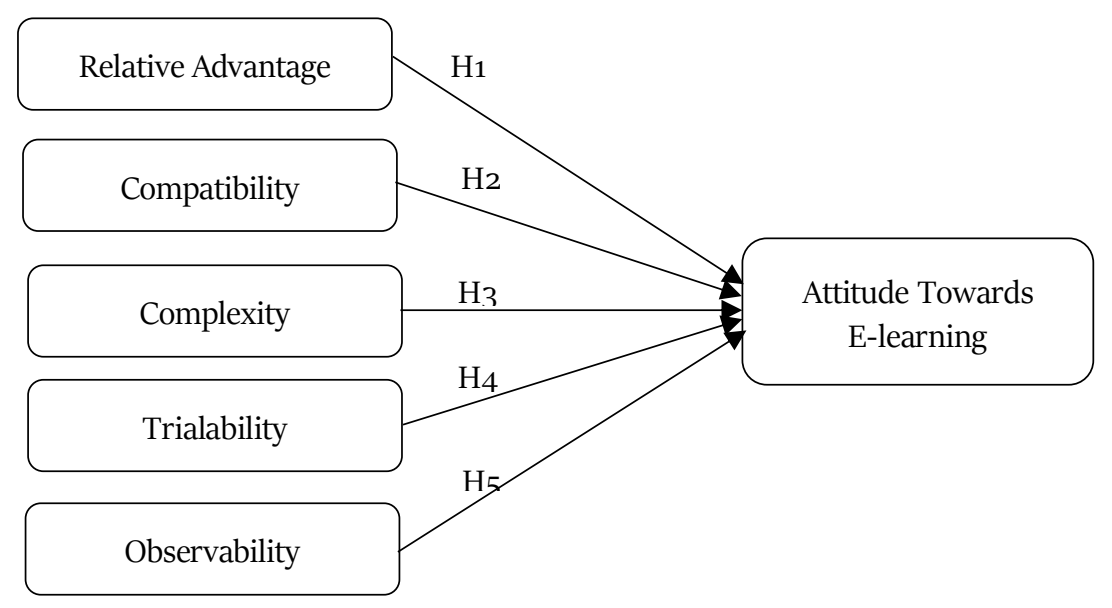

Figure 1. The research model adopted from Rogers (1995) and Duan et al. (2010)

\section{RESEARCH METHOD}

To achieve the research objectives, this research was designed using a mixed method: qualitative and quantitative. A qualitative method was used to identify the advantages and disadvantages of using e-learning from the users' perspective. The researchers interviewed 25 participants who have been using the e-learning system. The results of the interviews were tabulated and grouped according to the participants' answers. Based on these answers, there were 11 advantages and 10 weaknesses of e-learning indicators identified. These indicators were then combined with indicators from the literature review and used as the questions in the questionnaire and distributed to 313 respondents who have been using the e-learning system. In addition, to identify the advantages and weaknesses factors, a series of exploratory factor analysis was carried out.

A quantitative method was used to measure the influence of e-learning adoption on the attitude towards e-learning. Smart-PLS was utilized to identify the path between the attribute of innovation adoption and users' attitude toward e-learning. Quantitative methods were also used to answer the research hypotheses. The model of this research is depicted in Figure 1. The independent variables are innovation diffusion attributes consisting of five dimensions developed by Rogers (2003), namely; Relative Advantage, Compatibility, Complexity, Trialability, and Observability. One dependent variable is the attitude toward e-learning.

Table 1 shows the construct measurement and sources of reference for questionnaire development. The instrument of this study adopted the attributes of innovation adoption developed by Rogers (2003). The attitude scale used a scale developed by Davis (1989). This scale was used because it is in accordance with the object of the research, namely the adoption of elearning technology. All statements were measured using a Likert scale, ranging from 1 (strongly disagree) to 5 (strongly agree) 
Table 1. Construct measurement and sources

\begin{tabular}{lll}
\hline \multicolumn{1}{c}{ Construct } & \multicolumn{1}{c}{ Reference } \\
\hline 1. & Relative advantage & Rogers (2003); Duan et al. (2010); Lee et al. (2011) \\
2. & Compatibility & Rogers (2003); Duan et al. (2010); Zhang et al. (2010) \\
3. & Complexity & Rogers (2003); Duan et al. (2010); Zhang et al. (2010) \\
4. & Trialability & Rogers (2003); Duan et al. (2010); Lee et al. (2011) \\
5. & Observability & Rogers (2003); Duan et al. (2010); Zhang et al. (2010) \\
6. & Attitude & Davis (1989); Bruess (2003) \\
\hline
\end{tabular}

\section{RESULTS AND ANALYSIS}

The following results and discussion are based on the respondents' profile obtained during data collection. The gender distribution of respondents presented in Table 2 shows that the number of male respondents are 177 people (56.5\%) and female respondents are 136 people (43.5\%). It can be concluded that the distribution of respondents by gender is quite balanced.

Table 2 also shows the distribution of respondents based on the length of work. As many as $34.5 \%$ respondents have worked more than 20 years while $26.8 \%$ have worked between 5 and 10 years. Those who work under 5 years are only $11.8 \%$. The distribution of respondents based on education level shows that Master degree is $72.9 \%$ and Doctorate is $27.2 \%$. Distribution of respondents based on low to higher order rank shows that the majority of respondents are on IIIB group (27.8\%), IIID group (26.8\%), IIIC group (23.6\%) and the lowest was IVC group (1\%).

Table 2. Characteristics of the respondent

\begin{tabular}{cccc}
\hline Respondent profile & $\mathrm{N}$ & Frequency & Persentage \\
\hline Gender & 313 & & \\
Male & & 177 & 56.5 \\
Female & & 136 & 43.5 \\
Length of work & 313 & & \\
< 5 year & & 37 & 11.8 \\
5 to 10 year & & 84 & 26.8 \\
10 to 15 year & & 45 & 14.4 \\
15 to 20 year & & 39 & 12.5 \\
> 20 year & \multirow{3}{*}{313} & & 34.5 \\
Level of education & & 228 & \\
Master & & 85 & 72.9 \\
Doctorate & & 27.2 \\
Rank & 273 & 4 & \\
IIIA & & 87 & 1.3 \\
IIIB & 74 & 27.8 \\
IIIC & 84 & 23.6 \\
IIID & 15 & 26.8 \\
IVA & 6.8 \\
IVB & 3 & 1.9 \\
IVC & & & 1.0 \\
\hline
\end{tabular}




\section{Advantages and Weaknesses of E-learning}

To identify the advantages and disadvantages or weaknesses of e-learning, this study used a factor analysis. The result of the factor analysis is presented in Table 4 and 6 . The factor analysis using principal component analysis was conducted to determine the advantages of e-learning factors. Varimax rotation was used in this method and the cut-off value for factor loadings was set at a minimum of .40 as suggested by Tabanick and Fidell (1998). The advantages of e-learning factor analysis produced three factors with KMO o.836, Chi-Square value 1325,535, and Sig. 0.000 as shown in Table 3. The result indicates the appropriateness of the new factors formed.

Table 3. KMO and Bartlett's test the advantages of e-learning

\begin{tabular}{lll}
\hline Kaiser-Meyer-Olkin Measure of Sampling Adequacy. & 0.836 \\
& Approx. Chi-Square & 1325.535 \\
Bartlett's Test of Sphericity & df & 45 \\
& Sig. & 0.000 \\
\hline
\end{tabular}

Table 4 shows the results of the rotated component matrix with three new factors formed. The first factor consists of four indicators which are named as Flexibility, while the second and third factors consist of three indicators which are named as Attractiveness and Independent Learner. Eigenvalues, variance explained, cumulative variance explained and Cronbach's Alpha can be seen also in Table 4 .

Table 4. Rotated component matrix of the advantages of e-learning

\begin{tabular}{lccc}
\hline Indicators & Component & & \\
\cline { 2 - 4 } & Flexibility & Attractiveness & $\begin{array}{c}\text { Independent } \\
\text { Learner }\end{array}$ \\
\hline KU1 & & & \\
KU2 & 0.785 & & \\
KU3 & 0.761 & & \\
KU4 & 0.752 & & \\
KU8 & 0.588 & & \\
KU7 & & 0.843 & \\
KU6 & & 0.831 & \\
KU10 & & 0.828 & \\
KU11 & & & 0.834 \\
KU9 & & & 0.796 \\
Eigenvalue & & & 0.762 \\
Variance explained \% & 4.476 & 1.270 & 1.127 \\
Cumulative variance explained \% & 44.760 & 12.701 & 11.267 \\
Cronbach's Alpha & 44.760 & 57.462 & 68.729 \\
& 0.749 & 0.855 & 0.794 \\
\hline
\end{tabular}

The factor analysis using principal component analysis was also conducted to determine the weaknesses of e-learning. Varimax rotation was used and the cut-off value for factor loadings was set at a minimum of .40 as suggested by Tabanick and Fidell (1998). The factor analysis of elearning weaknesses produced three new factors with the value of KMO 0.749 , the value of ChiSquare 756,357 and Sig. 0.000 as shown in Table 5 indicating the feasibility of new factors formed. 
Table 5. KMO and Barttlet's test of the weakness of e-learning

\begin{tabular}{lll}
\hline Kaiser-Meyer-Olkin Measure of Sampling Adequacy. & 0.749 \\
& Approx. Chi-Square & 756.357 \\
Bartlett's Test of Sphericity & df & 36 \\
& Sig. & 0.000 \\
\hline
\end{tabular}

Table 6 shows the results of the rotated component matrix with three new factors formed. The first and second factors consist of three indicators which are labeled as 'Slow response' and 'High cost of internet', while the third factor consists of two indicators which are labeled as 'Limited internet coverage'. Eigenvalues, variance explained, cumulative variance explained and Cronbach's Alpha can be seen in Table 6.

Table 6. Rotated component matrix the weakness of e-learning

\begin{tabular}{lccc}
\hline Indicators & \multicolumn{3}{c}{ Component } \\
\cline { 2 - 4 } & $\begin{array}{c}\text { Slow } \\
\text { response }\end{array}$ & $\begin{array}{c}\text { High cost of } \\
\text { Internet }\end{array}$ & $\begin{array}{c}\text { Limited Internet } \\
\text { Coverage }\end{array}$ \\
\hline KL5 & 0.774 & & \\
KL4 & 0.762 & & \\
KL1 & 0.720 & & \\
KL9 & & 0.791 & \\
KL10 & & 0.766 & \\
KL8 & & 0.722 & \\
KL2 & & & 0.803 \\
KL7 & & & 0.717 \\
\hline Eigenvalue & 2.934 & 1.192 & 1.103 \\
Variance explained \% & 36.671 & 14.896 & 13.790 \\
Cumulative variance explained \% & 36.671 & 51.567 & 65.357 \\
Cronbach's alpha & .686 & .691 & .491 \\
\hline
\end{tabular}

\section{Measurement Model}

This study implemented SEM-PLS to measure the hypothetical relationships. The assessment of PLS-SEM model appropriateness was carried out using two stages: the measurement models and the structural models (Ali, Sarstedt, Rasoolimanesh, \& Ringle, 2018). The first stage was conducted by examining the reliability and validity of the construct. The purpose is to ascertain the reliability and standard indicator loadings. The loadings factor cut-off value is 0.7 , but loadings greater than 0.4 can be accepted (Hair, Hult, Ringle, \& Sarstedt, 2017). To determine internal consistency reliability, the value of composite reliability (CR) should be above 0.7 (Hair et al., 2017). In addition, the assessment of validity involved the evaluation of convergent validity and discriminant validity. Convergent validity can be determined through the average variance extracted (AVE) value which should be above 0.5 (Hair et al., 2017). The Heterotrait-Monotrait (HTMT) was used to assess discriminant validity with a cut-off value below 0.9 (Henseler, Ringle, \& Sarstedt, 2015). This study satisfies all measurement requirements, the results of the tests are depicted in Table 7 and Table 8.

Following the suggestion by Henseler, Hubona, and Ray (2016), evaluation of goodness of fit (GoF) model was conducted to ensure the appropriateness of the structural model. The GoF results are provided in Table 9 indicating the value of 0.484 . This GoF value is in a large category 
which means that the proposed model is fit with the data (Daryanto, Ruyter, \& Wetzels, 2010). Additionally, testing the fit model is also recommended to determine the approximate model fit. The approximate model fit in SEM-PLS was measured through standardized root mean square residual (SRMR) with a cut-off value of 0.08 as proposed by Hu \& Bentler (1999). Normed fit index (NFI) values above 0.9 are considered as acceptable (Byrne, 2013). In this study, the SRMR value is less than 0.08 and the NFI value is greater than o.9. Additionally, Henseler et al. (2016) note that the use of NFI is still uncommon.

Table 7. The loading, Cronbach's alpha (CA), composite reliability (CR), and AVE

\begin{tabular}{|c|c|c|c|c|c|c|}
\hline Variables and indicators & Loading* & Mean & St. Dev. & $\mathrm{CA}$ & $\mathrm{CR}$ & AVE \\
\hline Relative Advantage & & 3.926 & 0.354 & 0.616 & 0.791 & 0.560 \\
\hline RA1 & 0.776 & & & & & \\
\hline RA3 & 0.671 & & & & & \\
\hline RA5 & 0.792 & & & & & \\
\hline Compatibility & & 3.496 & 0.280 & 0.6270 & 0.798 & 0.569 \\
\hline COMP1 & 0.808 & & & & & \\
\hline $\mathrm{COMP}_{4}$ & 0.741 & & & & & \\
\hline $\mathrm{COMP}_{5}$ & 0.711 & & & & & \\
\hline Complexity & & 2.731 & 0.293 & 0.874 & 0.921 & 0.795 \\
\hline COMPLEX1 & 0.857 & & & & & \\
\hline COMPLEX2 & 0.946 & & & & & \\
\hline Trialability & 0.869 & $3 \cdot 441$ & 0.317 & 0.224 & 0.717 & 0.562 \\
\hline TRIAL1 & 0.816 & & & & & \\
\hline TRIAL3 & 0.677 & & & & & \\
\hline Observability & & $3 \cdot 472$ & 0.302 & 0.476 & 0.787 & 0.650 \\
\hline OBSERV1 & 0.881 & & & & & \\
\hline OBSERV2 & 0.724 & & & & & \\
\hline Attitude & & 4.258 & 0.409 & 0.840 & 0.894 & 0.681 \\
\hline ATTITUDE1 & 0.696 & & & & & \\
\hline ATTITUDE2 & 0.838 & & & & & \\
\hline ATTITUDE3 & 0.845 & & & & & \\
\hline ATTITUDE $4_{4}$ & 0.907 & & & & & \\
\hline
\end{tabular}

Note: *All significant at $p<0.01$

Table 8. Heterotrait-monotrait ratio of correlations (HTMT)

\begin{tabular}{lllllll}
\hline & 1 & 2 & 3 & 4 & 5 & 6 \\
\hline (1) Attitude towards e-learning & & & & & & \\
(2) Compatibility & 0.689 & & & & & \\
(3) Complexity & 0.211 & 0.511 & & & & \\
(4) Observability & 0.311 & 0.269 & 0.122 & & & \\
(5) Relative Advantage & 0.739 & 1.009 & 0.472 & 0.194 & & \\
(6) Trialability & 1.019 & 1.641 & 1.208 & 0.627 & 1.403 & \\
\hline
\end{tabular}

\section{Structural Model}

Completing the outer model evaluation with good results, the next step was assessing the structural model. The inner model evaluation was conducted by evaluating: coefficient of 
determination $\left(\mathrm{R}^{2}\right)$, cross-validated redundancy $\left(\mathrm{Q}^{2}\right)$, path coefficients and the effect size $\left(\mathrm{f}^{2}\right)$ (Hair, Sarstedt, Hopkins, \& Kuppelwieser, 2014). Further, Hair et al. (2014) note that $\mathrm{R}^{2}$ is a measure of model predictive accuracy, $\mathrm{Q}^{2}$ is a facility for assessing the inner predictive relevance of a model, path coefficients are values representing hypothesized relationships to link the constructs and $\mathrm{f}^{2}$ is a measure of effect for each path model. The percentage variation of exogenous variables confirmed by predictors is indicated by the coefficient of determination $\left(R^{2}\right)$ (Hair, Black, Babin, \& Anderson, 2010). The result of the inner test model is provided in Table 9. The table shows that the independent variable predictive accuracy on attitude toward e-learning is moderate (Hair, Ringle, \& Sarstedt, 2011). The five attributes of innovation diffusion can predict $37.0 \%\left(\mathrm{R}^{2}: 0.370\right)$ attitude toward e-learning. To assess the relevance of predictions, Henseler, Ringle, and Sinkovics (2009) state that $\mathrm{Q}^{2}$ values higher than zero provide evidence that the detected value is well reconstructed and the model has good predictive relevance. Table 9 shows that all $\mathrm{Q}^{2}$ values of innovation diffusion dimensions and attitude are positive. Thus, the predictions generated from the proposed model are appropriate. An $\mathrm{f}^{2}$ value was used to assess the contribution of the predictor variable to the $\mathrm{R}^{2}$ value of a target variable in the structural model. Criteria for $\mathrm{f}^{2}$ value is $0.35,0.15$, and 0.02 which represent strong, medium, and small effect size (Hair et al., 2017). The result of $\mathrm{f}^{2}$ shows that innovation diffusion has a medium effect size and small size effect on attitude (0.105 to 0.007 ).

Table 9. Goodness of Fit Index

\begin{tabular}{llll}
\hline Variable & AVE & $R^{2}$ & $Q^{2}$ \\
\hline Relative Advantage & 0.560 & & \\
Compatibility & 0.569 & & \\
Complexity & 0.795 & & \\
Trialability & 0.562 & & \\
Observability & 0.650 & & \\
Attitude Towards E-learning & 0.681 & 0.370 & 0.216 \\
\hline Average score & 0.636 & 0.370 & \\
AVE $\times R^{2}$ & & 0.235 & \\
GoF $=\sqrt{ }\left(\right.$ AVE $\left.\times R^{2}\right)$ & & 0.484 & \\
\hline
\end{tabular}

Next steps were assessing path coefficient significance and testing the hypotheses. Bootstrapping method was used to test path coefficients; Hair et al. (2011) suggest using 4999 bootstrap samples. Critical t-values for the two-tailed test are 1.65 (significance level at 0.1), 1.96 (significance level at 0.05) and 2.58 (significance level $=0.01$ ) (Hair et al., 2011). Figure 2 displays the estimated parameters of the model, and Table 10 shows the results of hypotheses test. Relative advantage dimension has coefficient value of 0.349 with $\mathrm{t}$-value of more than 1.96 on attitude toward e-learning, thus, $\mathrm{H}_{1}$ is accepted. Compatibility dimension has coefficient value of 0.227 with t-value of 2.924 on attitude, thus $\mathrm{H}_{2}$ is accepted. Trialability dimension has coefficient value of 0.153 with t-value of 2,097 on attitude, thus $\mathrm{H}_{4}$ is accepted. However, $\mathrm{H}_{3}$ and $\mathrm{H}_{5}$ are rejected as Complexity and Observability dimensions have low coefficient value (0.094 and 0.066) and tvalue below cut-off value of 1.96 respectively. 
Table 10. Results of the hypotheses testing

\begin{tabular}{lllll}
\hline & Path & Coefficient & t-value & Test result \\
\hline $\mathrm{H}_{1}$ & Relative advantage $\rightarrow$ Attitude towards e-learning & 0.349 & $4.804^{* *}$ & Accepted \\
$\mathrm{H}_{2}$ & Compatibility $\rightarrow$ Attitude towards e-learning & 0.227 & $2.924^{* *}$ & Accepted \\
$\mathrm{H}_{3}$ & Complexity $\rightarrow$ Attitude towards e-learning & 0.094 & 1.297 & Rejected \\
$\mathrm{H}_{4}$ & Trialability $\rightarrow$ Attitude towards e-learning & 0.153 & $2.097^{*}$ & Accepted \\
$\mathrm{H}_{5}$ & Observability $\rightarrow$ Attitude towards e-learning & 0.066 & 0.725 & Rejected \\
\hline
\end{tabular}

Note: ${ }^{* *}$ Significant at $p<0.01,{ }^{*}$ Significant at $p<0.05$

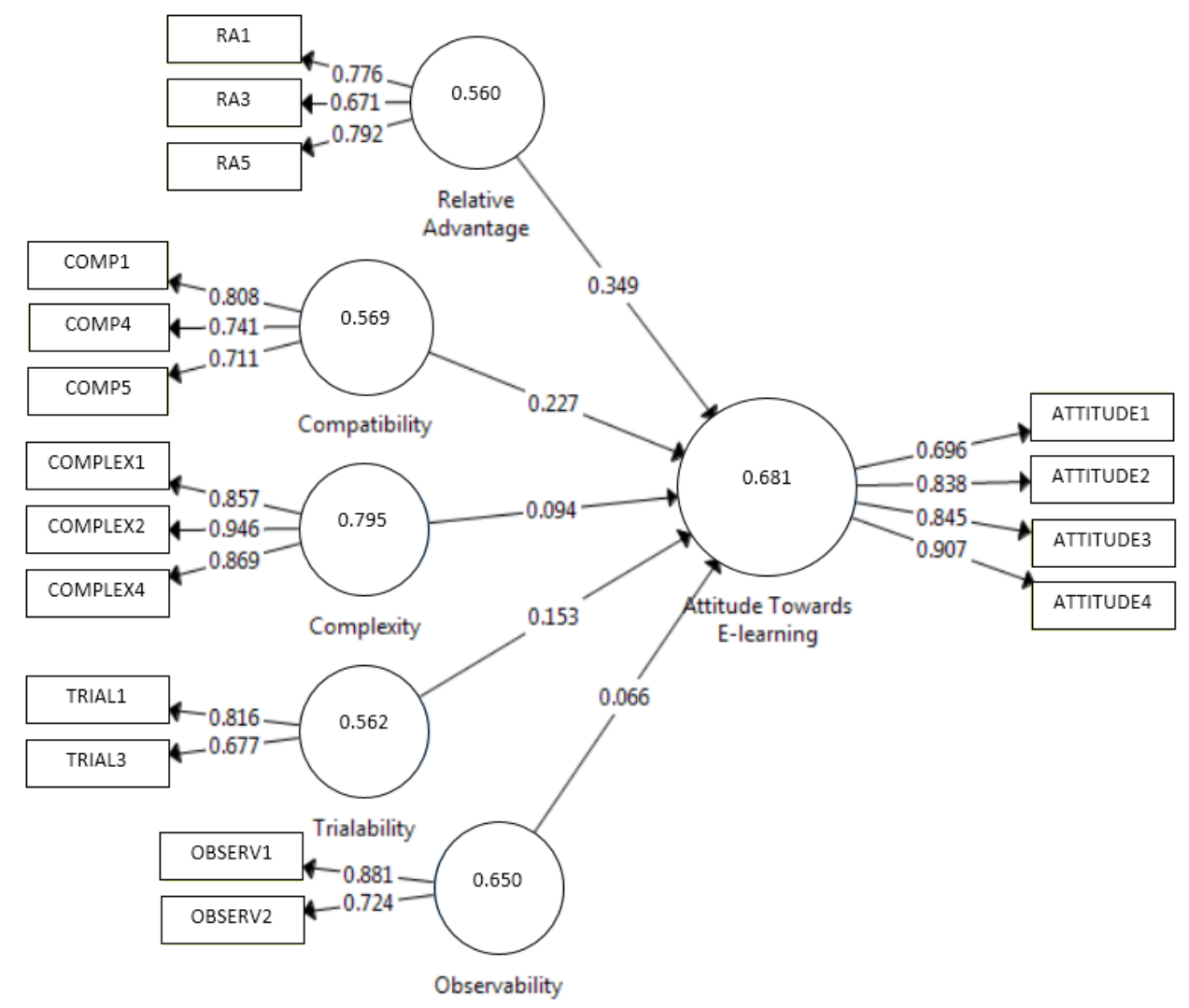

Figure 2. The structural model

\section{DISCUSSION}

First, this study has identified empirically the advantages and weaknesses of e-learning adoptions by forming new factors that contribute potentially to users' acceptance or rejection of e-learning innovation diffusion in education-based services businesses. Three new advantages factors were formed: 'Flexibility', 'Attractiveness' and 'Independent Learner'. These three factors are added to the list of e-learning advantages that have not been covered in previous researches. Thus, this finding extends previous studies by Chang (2016), Fernández et al. (2014), and Liaw and Huang (2013). Education-based business services should use these advantages to promote their teachinglearning service delivery. By promoting these advantages they will gain a competitive position 
over their rivals. Additionally, three new e-learning adoption weakness factors were also formed in this study. Those three weakness factors are 'Slow Response', 'High Cost of Internet' and 'Limited Internet Coverage'. These three weakness factors extend the previous study by Arkorful and Abaidoo (2015) who have identified e-learning weaknesses but did not mention the new weakness factors derive from the current study. By coping with these weaknesses, higher education-based business services should invest more on the internet infrastructure so that consumers can have more coverage and quick internet access. An investment on the internet infrastructure is only once but the benefits can be harvested immediately and for long-term.

Second, the hypotheses tests of this study have provided an empirical prediction on the relationship between innovation diffusion dimension and attitude toward e-learning. Relative Advantage, Compatibility and Trialability dimensions have a significant influence on attitude. However, Complexity and Observability dimensions have an insignificant influence on attitude. The results of this research are different from the previous research on the relationship between five innovation diffusion dimensions and attitude. Duan et al. (2010) study only shows two dimensions that have a significant influence on attitude: Compatibility and Trialability. Similarly, a study by Lee (2011) found that Observability and Compatibility dimensions did not provide a significant influence on attitude. These various results on these relationships imply that there is no consistency in the relationship between the dimension of innovation diffusion and attitude. Although the Innovation Diffusion Theory has been studied in many different contexts, more studies are still needed to validate the relationships between its variables. The findings of the current study are important for education-based business services as it sheds the light on the important dimensions of the innovation adoption and users' attitude. The finding provides a focus on education services on the variables that can be used to strengthen the competitiveness and dimensions that must be improved.

\section{MANAGERIAL IMPLICATION}

This study offers a useful direction for education-based business services managers to lift-up their organization competitive position by applying the advantage factors of e-learning adoption on their promotional activities. Specifically, they need to promote their teaching-learning delivery services using the advantage factors as their promotional tag line: 'Flexibility', 'Attractiveness' and 'Independent Learner'. At the same time, the organization also has to invest in the internet infrastructure to overcome the disadvantages e-learning components: 'Slow response', 'High cost of an Internet' and 'Limited Internet Coverage' of a network. This investment will be paid-off as the benefits outweigh the drawbacks. Investment on the internet infrastructure is once time investment for long-term usage. Thus, higher education-based business managers should have the courage to make a decision to invest their large funds and resources on advanced internet network designs, e-learning tools and software.

This study provides better insight for managers on the determinants of innovation diffusion dimensions. Managers should take these dimensions into consideration for the basis of making decisions to improve their education business services. More specifically, managers should use the three influential dimensions: 'Relative advantage', 'Compatibility' and 'Trialability' as the bases for their promotion themes. In promoting their education services, managers should combine these three influential dimensions with the advantages of using the e-learning system. Further, the dimensions that do not affect the attitude toward e-learning shall not be used in any promotional activities. Thus, by relying on the advantages and influential dimensions of 
innovation adoption results of this research, managers can create a superior position of their education services over their competitors.

\section{LIMITATION AND FUTURE RESEARCH}

Despite the important findings, this research also has limitations. First, the data of this study were collected only in Bandung and it was limited only to a small portion of higher education in the city, thus, it limits the generalization of the findings. Future research should involve more respondents from various educations business services. The present research data were gathered only from lecturers; future research may gather data both from students and lecturers. It is recommended also involving administrative staff as respondents. Second, it is also important to involve other variable influencing attitudes toward e-learning model. To establish a more comprehensive model, a future study might include other constructs beyond the innovation diffusion model by Rogers (2003). It might combine the model with TAM Model, UTAUT Model and TPB Model.

\section{REFERENCES}

Ali, F., Sarstedt, M., Rasoolimanesh, S. M., \& Ringle, C. M. (2018). An assessment of the use of partial least squares structural equation modeling (PLS-SEM) in hospitality research. International Journal of Contemporary Hospitality Management, 30(1), 514-538. doi: 10.1108/IJHM-10-2016-0558

Arkorful, V., \& Abaidoo, N. (2015). The role of e-learning, advantages and disadvantages of its adoption in higher education. International Journal of Instructional Technology and Distance Learning, 12(1), 29-42.

Boateng, R., Mbrokoh, A. S., Boateng, L., Senyo, P. K., \& Ansong, E. (2016). Determinants of elearning adoption among students of developing countries. The International Journal of Information and Learning Technology, 33(4), 248-262. doi: 10.1108/IJILTo2-2016-0oo8

Bouhnik, D., \& Marcus, T. (2006). Interaction in distance-learning courses. Journal of the American Society for Information Science and Technology, 57(3), 299-305. doi: 10.1002/asi.20277

Chang, V. (2016). Review and discussion: E-learning for academia and industry. International Journal of Information Management, 36(3), 476-485. doi: 10.1016/j.ijinfomgt.2015.12.007

Cheung, R., \& Vogel, D. (2013). Predicting user acceptance of collaborative technologies: An extension of the technology acceptance model for e-learning. Computers \& Education, 63, 16o175. doi: 10.1016/j.compedu.2012.12.003

Chu, T.-H., \& Chen, Y.-Y. (2016). With good we become good: Understanding e-learning adoption by theory of planned behavior and group influences. Computers \& Education, 92, 37-52. doi: 10.1016/j.compedu.2015.09.013

Daryanto, A., Ruyter, K. d., \& Wetzels, M. (2010). Getting a Discount or Sharing the Cost: The Influence of Regulatory Fit on Consumer Response to Service Pricing Schemes. Journal of Service Research, 13(2), 153-167.

Duan, Y., He, Q., Feng, W., Li, D., \& Fu, Z. (2010). A study on e-learning take-up intention from an innovation adoption perspective: A case in China. Computers \& Education, 55(1), 237-246. doi: 10.1016/j.compedu.2010.01.009 
Fernández, A., Peralta, D., Benítez, J. M., \& Herrera, F. (2014). E-learning and educational data mining in cloud computing: an overview. International Journal of Learning Technology, 9(1), 25-52.

Hair, J. F., Hult, G. T. M., Ringle, C., \& Sarstedt, M. (2017). A Primer on Partial Least Squares Structural Equation Modeling (PLS-SEM) (2 ed.). Thousand Oaks: Sage.

Hair, J. F., Sarstedt, M., Hopkins, L., \& Kuppelwieser, V. G. (2014). Partial least squares structural equation modeling (PLS-SEM) An emerging tool in business research. European Business Review, 26(2), 106-121.

Henseler, J., Hubona, G., \& Ray, P. A. (2016). Using PLS path modeling in new technology research: updated guidelines. Industrial Management \& Data Systems, 116(1), 2-20. doi: 10.1108/IMDS-09-2015-0382

Henseler, J., Ringle, C. M., \& Sarstedt, M. (2015). A new criterion for assessing discriminant validity in variance-based structural equation modeling. Journal of the Academy of Marketing Science, 43(1), 115-135.

Hussein, Z. (2017). Leading to Intention: The Role of Attitude in Relation to Technology Acceptance Model in E-Learning. Procedia Computer Science, 105, 159-164. doi: 10.1016/j.procs.2017.01.196

Lee, Y.-H., Hsieh, Y.-C., \& Hsu, C.-N. (2011). Adding innovation diffusion theory to the technology acceptance model: Supporting employees' intentions to use e-learning systems. Educational Technology \& Society, 14(4), 124-137.

Liao, H.-L., \& Lu, H.-P. (2008). The role of experience and innovation characteristics in the adoption and continued use of e-learning websites. Computers \& Education, 51(4), 1405-1416. doi: 10.1016/j.compedu.2007.11.006

Liaw, S.-S. (2008). Investigating students' perceived satisfaction, behavioral intention, and effectiveness of e-learning: A case study of the Blackboard system. Computers \& Education, 51(2), 864-873. doi: 10.1016/j.compedu.2007.09.005

Liaw, S.-S., \& Huang, H.-M. (2013). Perceived satisfaction, perceived usefulness and interactive learning environments as predictors to self-regulation in e-learning environments. Computers \& Education, 6o(1), 14-24. doi: 10.1016/j.compedu.2012.07.015

Makkonen, S., \& Johnston, J. (2014). Innovation adoption and diffusion in business-to-business marketing. Journal of Business \& Industrial Marketing, 29(4), 324-331. doi: 10.1108/JBIM-o82013-0163

Mantle-Bromley, C. (1995). Positive attitudes and realistic beliefs: Links to proficiency. The Modern Language Journal, 79(3), 372-386. doi: 10.1111/j.1540-4781.1995.tbo1114.X

Mohammadi, H. (2015). Investigating users' perspectives on e-learning: An integration of TAM and IS success model. Computers in human behavior, 45, 359-374. doi: 10.1016/j.chb.2014.07.044

Okazaki, S., \& dos Santos, L. M. R. (2012). Understanding e-learning adoption in Brazil: Major determinants and gender effects. The International Review of Research in Open and Distributed Learning, 13(4), 91-106. doi: 10.19173/irrodl.v13i4.1266

Park, S. Y. (2009). An analysis of the technology acceptance model in understanding university students' behavioral intention to use e-learning. Educational Technology \& Society, 12(3), 150162.

Rogers, E. M. (2003). Diffusion of innovations (5th Ed ed.). New York, NY, USA: The Free Press.

Rogers, E. M. (2004). A prospective and retrospective look at the diffusion model. Journal of health communication, 9(S1), 13-19. doi: 10.1080/10810730490271449 
Shee, D. Y., \& Wang, Y.-S. (2008). Multi-criteria evaluation of the web-based e-learning system: A methodology based on learner satisfaction and its applications. Computers \& Education, 50(3), 894-905. doi: 10.1016/j.compedu.2006.09.005

Tarhini, A., Masa'deh, R. e., Al-Busaidi, K. A., Mohammed, A. B., \& Maqableh, M. (2017). Factors influencing students' adoption of e-learning: a structural equation modeling approach. Journal of International Education in Business, 10(2), 164-182. doi: 10.1108/JIEB-09-2016-0032

Tosuntaş, Ş. B., Karadağ, E., \& Orhan, S. (2015). The factors affecting acceptance and use of interactive whiteboard within the scope of FATIH project: A structural equation model based on the Unified Theory of acceptance and use of technology. Computers \& Education, 81, 169178. doi: 10.1016/j.compedu.2014.10.009

Truong, H. M. (2016). Integrating learning styles and adaptive e-learning system: Current developments, problems and opportunities. Computers in human behavior, 55, 1185-1193. doi: 10.1016/j.chb.2015.02.014

Wang, W.-T., \& Wang, C.-C. (2009). An empirical study of instructor adoption of web-based learning systems. Computers \& Education, 53(3), 761-774.

Zhang, L., Wen, H., Li, D., Fu, Z., \& Cui, S. (2010). E-learning adoption intention and its key influence factors based on innovation adoption theory. Mathematical and Computer Modelling, 51(11), 1428-1432. doi: 10.1016/j.mcm.2009.11.01 